\title{
Cycle helmet wearing in teenagers-do health beliefs influence behaviour?
}

\author{
Mary Sissons Joshi, Kate Beckett, Aidan Macfarlane
}

The issue of cycle helmets continues to excite considerable debate among cycle enthusiasts, road safety officers, and medical practitioners. Some assert that the helmet constitutes an unambiguous safety gain, whereas others question this and focus on the broader social and political context of cycling, helmet use, and legislation.

As the BMA report Cycling Towards Health and Safety demonstrates, ${ }^{1}$ cycling offers young people a cheap, convenient, independent, and environmentally sound form of transport. It is also an excellent form of exercise that should be encouraged in light of The Health of the Nation targets, ${ }^{2}$ and particularly in view of recent research that points to low levels of fitness among contemporary teenagers. ${ }^{34}$ However, cycling on Britain's congested roads also involves risks to health through accident and injury. ${ }^{1}$ Cyclists aged 15-24 appear to be particularly at risk and indeed in Oxfordshire in 1993 accounted for $41 \%$ of reported accidents to cyclists aged 15 years and over. ${ }^{5}$ Males are disproportionately represented in these figures.

In Oxfordshire, more than half of young people's serious or fatal cycle accidents involve injuries to the head. ${ }^{6}$ Current debate about cycle helmets centres on the efficacy of helmets and the broader implications of their use. Some authors note that most cycle accidents are minor, and argue that enforced helmet use may deter people from using a bicycle and detract governments from providing safe provision for cyclists. ${ }^{7}$ In addition, considerable press coverage has been given to risk compensation theorists, who argue that cycle helmets decrease cyclists' safety by giving them a false sense of security which leads them to take more risks than they otherwise would. ${ }^{7-11}$ On the other hand, medical specialists are in little doubt that higher rates of cycle helmet wearing would radically reduce rates of serious injury and indeed save some lives. ${ }^{12} 13$ In a case-controlled study of children in Australia, Thomas et al conclude that wearing a helmet reduced the risk of head injury by $63 \%$ and loss of consciousness by $86 \%{ }^{14}$ In the UK, on the basis of their study in Cambridge, Maimaris $e t$ al conclude that 'the odds of head injury were significantly reduced, by a factor of three, by wearing a cycle helmet and the protective effect of wearing a helmet was present in all ages and all types of accidents, including motor vehicle accidents'. ${ }^{15}$

In 1993 Oxford City Council recorded a low helmet wearing rate of $13 \%$ among cyclists, including teenagers. Our study therefore aimed to discover what teenagers think about cycle helmets, the influences on wearing, and their attitudes towards prevailing counter arguments.

\section{Research details}

This research was guided by the health belief model ${ }^{16}$ and the theory of planned behaviour, ${ }^{17}$ which indicate that a person's intention to engage in a particular health behaviour relates not only to health beliefs but also to a host of other factors such as risk perception, social norms, beliefs about costs and benefits, and the extent to which the behaviour is believed to lie within personal control.

After open ended discussion groups with teenagers at local schools, we designed a user friendly questionnaire to investigate the relationship between attitudes to cycle helmets and helmet use. This questionnaire was completed by 655 cyclists aged $14-18$ years in four large secondary schools in Oxford (two coeducational comprehensive schools, one boys private secondary school, and one girls private secondary school). Our sampling procedure enabled us to infer a cycling rate of $86 \%$ among this age group in Oxford. This extremely high rate of cycling was found equally among males and females. The mean age of the sample was 15 years, and most cite 'travel/getting around' rather than 'leisure/racing/fitness' as their major reason for cycling.

\section{Helmet use}

Fifty three per cent of the cyclists surveyed never wore a cycle helmet and although $47 \%$ of the cyclists reported wearing a helmet, only $18 \%$ always wore one when cycling. Males and females were equally likely to wear a helmet, but use declined systematically with age, falling from $52 \%$ at age 15 and under to $38 \%$ at age 17 and over $(p<0.01)$. (Significance levels reported refer to $x^{2}$ tests.) Helmet wearers were more likely to wear seat belts in the back 
Table 1 Multiple regression on helmet wearing

\begin{tabular}{llrl}
\hline Variable & $\beta$ & \multicolumn{1}{c}{$t$} & \multicolumn{1}{c}{ Sig $t$} \\
\hline Active consideration & 0.4347 & 12.22 & $<0.0001$ \\
Anticipated regret & 0.1989 & $5 \cdot 33$ & $<0.0001$ \\
Conformity & 0.0811 & $2 \cdot 22$ & $<0.0271$ \\
(Constant: 2.81) & & 32.15 & $<0.0001$
\end{tabular}

Variables not predictive of helmet wearing: beliefs about effectiveness and value placed on outcome, social norms and motivation to comply with those norms, extent to which the behaviour is believed to be within personal control, perceived vulnerability, and political considerations (sample size $=655$, proportion of variance explained/Adj Rsq $=0 \cdot 31$ ).

of cars $(p<0.001)$ and were less likely to smoke $(\mathrm{p}<0.001)$.

\section{Attitudes to helmets}

Helmet wearers and non-wearers believed equally in the efficacy of helmets and $96 \%$ thought that wearing a helmet would reduce the risk of serious head injury. They also agreed with the statement that they 'didn't want to have a head injury'. So it is not surprising that even $54 \%$ of the non-wearers thought they ought to wear a helmet. On the negative side, $71 \%$ of our sample thought that helmets looked ridiculous, and $81 \%$ found them hot and uncomfortable. Both groups said that helmets spoilt the sense of freedom you get on a bike. Moreover, both groups shared the same norms pertaining to helmet use, reporting that their parents pressed them to wear one, and friends discouraged them. In addition, $67 \%$ of our sample agreed that 'although cycling is an everyday activity it is very risky'. But these beliefs were not predictive of helmet use. So why are wearing rates so low with $53 \%$ of the sample never wearing a helmet and $13 \%$ only wearing one occasionally?

\section{Predictors of helmet use}

Multiple regression suggests that three attitudinal factors distinguish between wearers and non-wearers (table 1). The first can be described as the amount of active consideration given to the subject. Altogether $54 \%$ of non-wearers (compared with $16 \%$ of wearers) said that they have 'so many issues to think about these days that cycle helmets are pretty low' on their agendas, and $52 \%$ of non-wearers reported that when they get on their bikes 'the last thing' they thought about was whether to wear a helmet or not. This does not imply

Table 2 Multiple regression on intention to wear a helmet

\begin{tabular}{llll}
\hline Variable & $\beta$ & $t$ & \multicolumn{1}{l}{ Sig $t$} \\
\hline Active consideration & 0.2841 & 5.19 & $<0.0001$ \\
Conformity & 0.2092 & 3.99 & 0.0001 \\
Anticipated regret & 0.1752 & 3.35 & 0.0009 \\
Perceived vulnerability & 0.1183 & 2.03 & 0.0437 \\
(Constant: 1.41) & & 3.51 & 0.0005
\end{tabular}

Variables not predictive of intention to wear a helmet: beliefs about effectiveness and value placed on outcome, social norms and motivation to comply with those norms, extent to which the behaviour is believed to be within personal control, and political considerations (sample size $=345$, proportion of variance explained/Adj $\mathrm{Rsq}=0 \cdot 28$ ). that non-wearers have never thought about helmets, or indeed that they are ignorant about them, but that they just don't think about them as a rule.

The second factor which distinguished between the two groups was anticipated regret. ${ }^{18}$ In our study this is characterised by their response to the statement 'I would never forgive myself if I had an injury that could have been prevented by wearing a helmet'. Helmet wearers were significantly more likely than non-wearers to agree with this statement; this was particularly pronounced among females. Thus it would appear that the ability to imagine yourself in this situation has a positive relationship with helmet wearing.

The third factor explaining helmet wearing can loosely be called conformity. Sixty five per cent of helmet wearers compared with $45 \%$ of non-wearers said that they were more likely to wear a helmet if their friends also wore them. Furthermore, $77 \%$ of wearers compared with $63 \%$ of non-wearers agreed that 'If helmets were compulsory, you'd be able to wear one without feeling a wally'.

\section{Predictors of intention to wear a helmet} It could be argued that the attitudes of those who already wear a helmet are post hoc rationalisations of behaviour and do not necessarily reveal the attitudes that motivated them to become helmet wearers. Non-wearers were therefore asked to comment on whether they intended to start wearing a helmet in the near future. Some $19 \%$ replied that they possibly/probably/definitely intended to wear a helmet, $27 \%$ were unsure, and $54 \%$ stated that they possibly/probably/definitely did not intend to wear a helmet. The intention to wear a helmet was greater among females than males $(24 \% v 16 \% \mathrm{p}<0.01)$. Multiple regression reveals that just as helmet wearers were distinguished from non-wearers by an active consideration of the issues, anticipated regret and a desire to be one of the crowd, so too were those who intended to wear a helmet in comparison with those who did not intend to wear a helmet (table 2). But a fourth factor, how vulnerable cyclists perceived themselves to be, also effects intention. Non-wearers believed that they were vulnerable to cycle accidents. But those non-wearers who believed themselves to be more vulnerable had a greater intention to wear a helmet than the other nonwearers. However, as vulnerability is not predictive of actual helmet wearing, it can be seen that perceived vulnerability is merely related to good intention but not to behaviour.

\section{Does accident experience effect helmet use?}

Pilot work in the same schools suggested that experience of injury leads some cyclists (or their parents) to buy a helmet but only exerts a temporary effect on helmet use. Among the entire sample, $14 \%$ had experienced a cycle accident (16\% males and $11 \%$ females) which necessitated a visit to either a casualty 
department or their general practitioner and $22 \%$ knew of someone who had died in a cycle accident. But the questionnaire established that there was no relationship between helmet use and personal experience of a cycle accident or knowing of someone who has died in a cycle accident.

In a further question we asked the teenagers to rate themselves as cyclists and $13 \%$ of males and $4 \%$ of females rated themselves as 'reckless' (as opposed to safe enough, careful, or over cautious). But those cyclists who rated themselves as reckless were found to be less likely to wear a helmet than the rest of the sample $(p<0.001)$, and more likely to have experienced an accident $(p<0.01)$.

\section{Should helmets be mandatory?}

The questionnaire also addressed the question of 'mandatory helmet wearing' imposed either by schools or by law. We were able to compare helmet wearing among boys at a school where helmets were compulsory if riding to school, with boys at a school where they were not. Fifty three per cent of boys at the mandatory school, as opposed to $38 \%$ at the nonmandatory school, reported wearing a helmet. However, this difference related only to cycle journeys to and from school as helmet use in general was lower in both groups and did not differ between schools. This demonstrates that, for this age group, school compulsion only enhances wearing rates on the journey to school, but does not alter underlying attitudes towards helmets or effect helmet wearing on non-school journeys.

The interplay between school compulsion and norms can result in seemingly irrational behaviour. This was nicely demonstrated by a 16 year old at the girls' school in our study where helmets were compulsory but only until the sixth form when they become optional. She said 'Before the sixth form 1 used to leave home with my helmet on, take it off just around the corner, and put it on again as I got to the school gates'. Now older 'I leave home with it on and cycle to school with it on, but I take it off as I approach the school' as this demonstrates sixth form status. Role models are important and it is clear that young cyclists are most unlikely to wear helmets unless adults do so too.

When asked about legislation to enforce helmet use, $55 \%$ of the entire sample felt that helmet wearing 'should be made law'. Indeed general opinion among the teenagers was that no other method (such as health education campaigns, improving helmet design, etc) would work. As one pupil commented 'I think that they should just get on and make it law ... it's the only way to make enough people wear them'. There was, however, a considerable sex difference in attitude to legislation. Among females, $80 \%$ of wearers and $63 \%$ of non-wearers supported legislation. Among males, $59 \%$ of wearers but only $34 \%$ of non-wearers supported legislation. But the majority of non-wearers $(73 \%$ of females and $59 \%$ of males) said that they would comply with helmet legislation. Only $6 \%$ of nonwearers said they would stop cycling if helmet wearing became compulsory.

\section{Disincentives to helmet use}

On the issue of risk compensation, it is difficult to measure actual behaviour, but only $19 \%$ of our sample believed that helmets would or do make them cycle more dangerously. Fifteen per cent thought that motorists would treat cyclists with helmets less cautiously and $30 \%$ thought that helmets, by making them more conspicuous, would cause motorists to give them a wider berth.

Finally, we looked at more tangible factors that are frequently cited as reasons for nonwearing, such as cost and inconvenience. Seventy three per cent stated that if they wanted to buy a helmet they would be prepared to spend $£ 20$ or under, and $60 \%$ of non-wearers claimed that the current price of a helmet (approximately $£ 35$ at the time of the study) is a factor in their not wearing one. Seventy per cent claimed that the inconvenience of carrying a helmet around was a major obstacle and $36 \%$ said that they would be more likely to wear a helmet if their school/college provided somewhere to keep it.

\section{General discussion}

Most teenagers sampled believed in the efficacy of cycle helmets and thought that they ought to wear one. But only $18 \%$ of the sample wore a helmet on every cycle journey. As has so frequently been demonstrated the relationship between health knowledge and behaviour change is problematic. ${ }^{17} 19-21$ Our survey suggests that neither beliefs in the effectiveness of helmets nor perceiving oneself to be at risk are predictive of helmet wearing. These may be necessary but not sufficient determinants of behaviour.

In Oxford, there are exceptionally high rates of cycling among teenagers but helmet wearing rates are low. It should not be assumed, however, that non-wearers are irresponsible cyclists. Two thirds use cycle routes where they were available, and more than half alter their routes to avoid heavy traffic and go out of their way to avoid potential points of conflict such as roundabouts and major intersections. The survey demonstrates that where provisions are made for cyclists they will be well used.

Most of our sample rejected the notion that helmets would or do cause them to increase their risk taking behaviour. Their views are confirmed by a study of cyclists in Australia, which found no increase in risk taking behaviours after helmet legislation. ${ }^{22}$ While Australian material suggests that helmet legislation deters teenagers (but not any other age group) from cycling, ${ }^{23}$ our own data suggest that this would not be the case in the $\mathrm{UK}$ as this age group cycle primarily for transport rather than for leisure.

Further research needs to address the role of perceived vulnerability. The majority of helmet wearers and non-wearers agree with the 
statement that 'although cycling is an everyday activity it is very risky'. However, Weinstein has noted that lay thinking is characterised by unrealistic optimism about one's own vulnerability in comparison with that of others, for example through exaggerated notions of one's own skill. ${ }^{24}$ Comments to open ended questions revealed some non-wearers engaging in this type of reasoning, stating for example that, 'There is the feeling that it could never happen to me because I'm a safe cyclist'.

Important gender differences are revealed by these data. Males are more likely to regard themselves as reckless and indeed are more likely to have had a cycle accident. However, among those who do not wear helmets, males are less supportive of helmet legislation and are less willing to comply with legislation than females. They are also likely to be more optimistic citing their own skill as mediating the risk of an accident. In this respect young male cyclists are subject to the illusion of control' bias characteristic of young male drivers. ${ }^{25}$ Health education in this domain will probably need to be gender specific. Focusing on teenagers as a homogeneous group ignores important sex differences in attitudes to risk.

\section{Policy and health education implications}

Our data also suggest that in order to be effective health education in this domain should concentrate less on simple information concerning the efficacy of the helmet and more on material aimed at encouraging the nonwearers to contemplate how they would feel if they sustained an injury that could have been prevented or lessened with the use of a helmet. Serious or fatal cycle accidents are rare, but to engage in preventative health behaviour the individual must believe that the rare event might happen. Health education needs to stress the randomness of cycle accidents, the vulnerability of all cyclists, and emphasise within the health message that it might happen to you'.

We should not be too optimistic, however, about the extent to which health education can increase helmet use. Even very imaginative health education may not overcome the compelling counter pressures that operate in this area. Health education, nevertheless, may be crucial in raising awareness before helmet legislation and in increasing wearing rates to a level where legislation becomes more acceptable. But the history of seat belts suggests that helmet legislation will ultimately be required if higher rates of use are desired. ${ }^{26}$

In conclusion, as cyclists (with the exception of young children) are least often at fault in the accidents in which they are involved, ${ }^{27}$ and as helmets do not protect against all classes of injury, it is essential that any move towards greater helmet use must be accompanied by a comprehensive package of other measures to protect cyclists from the speed and manoeuvres of motorised road users.

We would like to thank pupils and staff at Cheney School, Cherwell School, Magdalen College School, and the Oxford High School for their cooperation in this study. We are also indebted to the Oxford Regional Health Authority and the Road Safety Section of Oxfordshire County Council for funding.

1 Hillman M. Cycling towards health and safety. London: BMA, 1992.

2 The health of the nation: a strategy for health in England. London: HMSO: 1992. (Government white paper.)

3 Armstrong N. Independent mobility and children's physical development. In: Hillman $\mathbf{M}$, ed. Children, transport and the quality of life. London: Policy Studies Institute, 1993.

4 Allied Dunbar. National fitness survey. London: Allied Dunbar, Health Education Authority, Sports Council, 1992.

5 Hook D. Road casualty report 1993/1994. Oxford: Oxfordshire County Council, Road Safety Group, 1994.

6 Mills P. Pedal cycle accidents - a hospital based study. Crowthorne: TRRL, Department of Transport, 1989.

7 Hillman M. Cycle helmets: the case for and against. London: Policy Studies Institute, 1993.

8 Adams JGU. Risk homeostasis and the purpose of safety regulation. Ergonomics 1988; 31: 407-28.

9 Davis R. Death in the streets: cars and the mythology or road safety. Hawes, North Yorkshire: Leading Edge, 1983.

10 Wilde G. Beyond the concept of risk homeostasis: suggestions for research and application towards the prevention of accidents and life-style related disease. Accident Analysis and Prevention 1986; 18: 377-401.

11 Adams J. Risk and freedom: the record of road safety regulation. London: Transport Publishing Projects, 1985.

12 Thompson RS, Rivara FP, Thompson DC. A case-control study of the effectiveness of bicycle safety helmets. $N$ Engl study of the effectiveness of
JMed $1989 ; 320: 1351-67$.

13 Simpson HRW, Mineiro J. Prevention of bicycle accidents. Injury 1992; 23: 171-3.

14 Thomas S, Acton C, Nixon J, Battistutta D, Pitt WR, Clark $R$. Effectiveness of bicycle helmets in preventing head injury in children: case-controlled study. $B M \mathcal{F} 1994$; 308: 173-5.

15 Maimaris C, Summers CL, Browning C, Palmer CR. Injury patterns in cyclists attending an accident and emergency wearers. $B M \mathcal{F}$ 1994; 308: 1537-40.

16 Rosenstock IM. Why people use health services. Millbank Memorial Fund Quarterly 1966; 44: 94-127.

17 Ajzen I, Madden TJ. Prediction of goal-directed behaviour: Attitudes, intentions and perceived behavioural control. Attitudes, intentions and perceived beh

18 Richard R, Van der Plight J, De Vries N. Anticipated affective reactions and prevention of AIDS. Br $\mathcal{F}$ Soc Psychol 1995 (in press)

19 Fishbein M, Ajzen I. Belief, attitude, intention and behavior: an introduction to theory and research. Reading, MA: Addison-Wesley, 1975.

20 Kirscht JP. Preventive health behavior: a review of research issues. Health Psychol 1983; 2: 277-301.

21 Nutbeam D, Macaskill P, Smith C, Simpson JM, Catford J. Evaluation of two school smoking education programmes under normal classroom conditions. BMF 1993; 306: $102-7$.

22 Walker MB. Law compliance and helmet use among cyclists in New South Wales, April 1991. For the Roads and Traffic Authority, New South Wales, Australia: Road Safety Bureau Consultant Report CR 1/91.

23 Cameron M, Heiman L, Neiger D. Evaluation of the bicycle helmet wearing law in Victoria during its first 12 months. (Report No 32.) Monash University, Australia: Accident Research Centre, July: 1992.

24 Weinstein ND. Unrealistic optimism about future life events. F Pers Soc Psychol 1980; 39: 806-20.

25 McKenna F. It won't happen to me: unrealistic optimism or the illusion of control? Brf Psychol 1993; 84: 39-50.

26 Taylor SE. Health psychology. New York: McGraw, 1991.

27 Carsten OMJ, Tight MR, Southwell MT, Plows B. Urban accidents: why do they happen? Basingstoke: AA Foundation for Road Safety Research, 1989. 